\title{
Oculo-auriculo-vertebral spectrum associated to progressive external ophthalmoplegia. Biological, laboratory, electrophysiological and clinical aspects
}

\author{
Agostino Berio, ${ }^{1}$ Giacomo Garlaschi, ${ }^{2}$ Gian Luigi Mariottini, ${ }^{3}$ Enrico Calcagno, ${ }^{4}$ Attilia Piazzi ${ }^{1}$ \\ ${ }^{1}$ Department of Neurosciences, Rehabilitation, Ophthalmology, Genetics and Mother-Child Sciences; ${ }^{2}$ Department of \\ Health Sciences; ${ }^{3}$ Department of Earth, Environment and Life Sciences; ${ }^{4}$ Department of Surgical Sciences and \\ Integrated Diagnostics, University of Genoa, Italy
}

\begin{abstract}
The authors discuss about the relationships between oculoauriculo-vertebral spectrum (OAVS), a malformative condition affecting eyes, ears and vertebral structures mainly derived from neural crests, and autosomal dominant progressive external ophthalmoplegia (adPEO) - an electron transport chain disorder characterized by palpebral ptosis and muscular symptoms - on the basis of laboratory data and clinical signs in a case belonging to a family in which symptoms of both diseases occur. Hemifacial microsomia and ears abnormalities were the main neural crest cells (NCC) derived signs for OAVS diagnosis. Palpebral ptosis and the associated hyperlactacidemia with high Lactate to Pyruvate ratio were main signs for the suspicion of adPEO, but the diagnosis was proposed by clinical, biochemical, electrophysiological and genetic
\end{abstract}

Correspondence: Agostino Berio, Department of Neurosciences, Rehabilitation, Ophthalmology, Genetics and Mother-Child Sciences, University of Genoa, via G. Gaslini 5, 16145 Genoa, Italy.

Tel.: +39.010.56362248

E-mail: agostinoberio@gaslini.org

Key words: Oculo-Auriculo-Vertebral Spectrum; Lactacidemia; Pyruvicemia; Lactate to Pyruvate ratio; Malformation; Progressive external ophthalmoplegia.

Contributions: the authors contributed equally.

Conflict of interest: the authors declare no potential conflict of interest.

Funding: none.

Received for publication: 2 December 2017.

Revision received: 15 March 2018.

Accepted for publication: 6 April 2018.

C) Copyright A.o Berio et al., 2018

Licensee PAGEPress, Italy

Journal of Biological Research 2018; 91:7214

doi:10.4081/jbr.2018.7214

This article is distributed under the terms of the Creative Commons Attribution Noncommercial License (by-nc 4.0) which permits any noncommercial use, distribution, and reproduction in any medium, provided the original author(s) and source are credited. methods because the biopsy not always is diagnostic, as in our case. The association of two groups of symptoms (malformed, NCCrelated, and myopatic-electron transport related) in the same subject as observed in our case and partially in the family, may be ascribed to nuclear abnormalities and mitochondrial electron transport disorder, respectively, as well as to a possible common etiopathogenetic mechanism. In some cases of OAVS, the malformations may be consequent to oxidative phosphorilation disease (OXPHOS) derangement, as previously demonstrated; the extensive determination of lactacidemia may be important to address the research on OAVS patients in the mitochondrial/OXPHOS genetic domain, with advantage in the knowledge of OAVS pathogenesis.

\section{Introduction}

Oculo-Auriculo-Vertebral Spectrum $(\mathrm{OAVS})^{1}$ is a disease mainly of cranio-facial morphogenesis having a prevalence of 1:3500 birth, ${ }^{2}$ and involving structures derived from the first and the second branchial arches ${ }^{3-5}$ which are connected to neural crest cells (NCC) development. ${ }^{6-10}$

OAVS includes variable abnormalities of facies, eyes, ${ }^{7}$ ears and vertebral ${ }^{11}$ structures ranging from mild to severe. Other features, such as cardiac, ${ }^{12}$ urogenitary, ${ }^{11}$ limbs and cerebral malformations, ${ }^{3,13}$ are present; facial palsy, strabismus, microphthalmia, and velopalatal insufficiency were also reported. ${ }^{3,13}$

The diagnosis of OAVS is clinical, because gene(s) responsible are still unknown. ${ }^{2}$ The minimal signs to establish the diagnosis are microtia associated or not to hemifacial microsomia. ${ }^{2,12}$ Isolated hemifacial microsomia associated to a family history of OAVS was suggested to be consistent with the diagnosis of OAVS. ${ }^{2}$ The disease is frequently sporadic, but familial cases with apparent dominant or recessive autosomal inheritance ${ }^{2,13}$ are reported.

Segregation analyses have suggested an autosomal dominant mode of inheritance with reduced penetrance. ${ }^{14,15}$ Familial cases and various chromosome aberrations reports depose for a genetic basis in OAVS, but environmental and epigenetic factors may be important. $^{2}$

Microtia is a common phenotype in OAVS ${ }^{12,13,16}$ and, as for maxillary hypoplasia, it is consequent to cranial NCC defect. , $^{3,4,13}$

Aim of this work is to report on a OAVS case with two other patients in the same family, with symptoms connected to OAVS spectrum and to progressive external ophthalmoplegia (PEO), ${ }^{14,16-}$ 18 a disease of electron transport of the respiratory chain (i.e. oxidative phosphorilation disease, OXPHOS), and to study the 
possible common etiopathogenetic mechanism of OAVS and PEO. These cases showed the minimal criteria for the diagnosis of OAVS in two generations, a condition for considering a dominant mode of inheritance. In a case, OAVS was associated to typical PEO, a respiratory chain disorder

\section{Materials and Methods}

We studied a family composed by six subjects, some of them having mainly facial malformations, but also of other organs, or other connected symptoms.

Lactacidemia, pyruvicemia, glycemia, and mucopolysaccharides were examined by commonly commercial available tests. Muscular biopsy was performed on left quadriceps; fibres were stained by hematoxilin-eosin, trichrome of Gomory, oil red, PAS, PAS-diastasis, NADH, SDH, Cox, AMDA, PFK, Phosphorilase, acid phosphatase, alkaline phosphatase, esterases, ATPase. The cariotype staining for $\mathrm{G}$ banding was performed by $\mathrm{qFq}$, with band resolution 400 , and metaphases analyses 16 . For the analysis of $\mathrm{X}$ fragile gene, FMR1 gene was studied by PCR, Southern Blot, enzyme restriction and DNA extraction. Array Genomic Hybridization (AGH) was performed by Agilent 400k with medial resolution of $5.3 \mathrm{~Kb}$ and analyzed by AGH Analytics Software (v. 3.4-40). Map position refers to genome assembly hg 19, and subsequently by Array genomic hybridization, analyzing all genome with resolution $1 \mathrm{~Kb}$.

\section{Results}

\section{Studied cases}

The family history signaled palpebral ptosis in a grand-aunt of mother of proposita, diabetes in another maternal grand-aunt, and diabetes in a paternal grand-uncle. The proposita (patient II-2) was born from unrelated parents (mother with gestosis), by caesarean

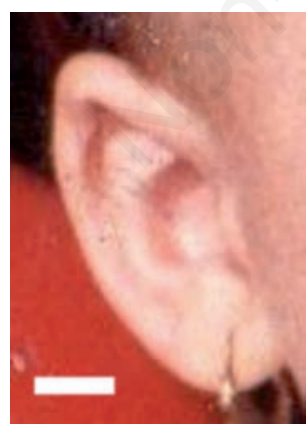

Figure 1. Typical feature of the external ear of proposita: little, down sided, and semplified ear with hypoplastic lobule. Bar: $1 \mathrm{~cm}$. section due to uterus atonia, weight $3,250 \mathrm{~g}$, head circumference $38.0 \mathrm{~cm}$; at birth she presented respiratory distress. At nineteen months of age clinical examination of the patient showed macrocrania, frontal bossing, hemifacial microsomia (right $<$ left), right eye microphthalmia with palpebral ptosis and convergence weakness (with subsequent operated strabismus), antimongoloid palpebral slant, malar hypoplasia, malformed, little and simplified ear low side bilaterally with hypoplastic lobule (Figure 1), flat nasal root, dental malocclusion, irregular teeth with enamel hypoplasia. The patient presented hypernasal voice due to a fissure between velum and posterior pharingeal wall, persisting during fonation. Dysphagia was present. Muscular hypotonia, mainly of inferior limbs, weak Achilles reflex, and surgically treated bilateral pes planus-valgus pronatus were present. Hydrocephalus with cortical atrophy was diagnosed by Computed Tomography (CT). Subsequently, vertebral abnormalities with spondilolysis and spondilolysthesis, lumbar hyperlordosis and scoliosis, and generalized myopathy, worsened with age, were diagnosed. Trasmissive hypoacusia was also reported. Cardiological, nephrological and pulmonary malformations were not demonstrated. Development and mild mental delay (IQ=75) were present. Pubertas precox at four years and six months of age was diagnosed and treated by Suprefact. The patient experienced subsequent constant oligomenorrea.

EEG was normal. Laboratory tests carried out during the period of observation showed normal CPK, intermittent hyperlactacidemia (20.0-33.7 mg/dL; normal values: $<20 \mathrm{mg} / \mathrm{dL})$, pyruvicemia variable from $0.24-0.82 \mathrm{mg} / \mathrm{dL}$ (normal value $<0.5 \mathrm{mg} / \mathrm{dL}$ ) and high Lactate to Pyruvate $(\mathrm{L} / \mathrm{P})$ ratio (in basic conditions=54). After glycidic meal containing fructose, lactacydemia showed a higher value (from 29.1 to $34.4 \mathrm{mg} / \mathrm{dL}$ after one hour) followed by slow decrease $(33.10 \mathrm{mg} / \mathrm{dL}$ after three hours) (Tables $1-3)$. In other controls after meal L/P values were also higher (up to 158 ); after

Table 1. Trend of lactacydemia (L), pyruvicemia (P), Lactate to Pyruvate $(\mathrm{L} / \mathrm{P})$ ratio, and glycemia in basal conditions and after meal containing fructose and other carbohydrates.

$\begin{array}{lcc}\text { Basal } & 1 \text { hour after meal } & \text { 3 hours after meal } \\ \mathrm{L}=29.1 \mathrm{mg} / \mathrm{dL} & \mathrm{L}=34.40 \mathrm{mg} / \mathrm{dL} & \mathrm{L}=33.10 \mathrm{mg} / \mathrm{dL} \\ \mathrm{P}=0.53 \mathrm{mg} / \mathrm{dL} & \mathrm{P}=0.94 \mathrm{mg} / \mathrm{dL} & \mathrm{P}=0.88 \mathrm{mg} / \mathrm{dL} \\ \mathrm{L} / \mathrm{P}=54 & \mathrm{~L} / \mathrm{P}=36 & \mathrm{~L} / \mathrm{P}=37 \\ \text { Glycemia=81 mg/dL } & \text { Glycemia }=67 \mathrm{mg} / \mathrm{dL} & \text { Glycemia }=74 \mathrm{mg} / \mathrm{dL}\end{array}$

Table 2. Lactacydemia (L), pyrovicemia (P), and Lactate to Pyruvate ratio $(\mathrm{L} / \mathrm{P})$ in basal conditions in parents of the proposita.

\begin{tabular}{llll} 
& Lactacydemia & Pyruvicemia & L/P ratio \\
Father & $\mathrm{L}=27.60 \mathrm{mg} / \mathrm{dL}$ & $\mathrm{P}=0.54 \mathrm{mg} / \mathrm{dL}$ & $\mathrm{L} / \mathrm{P}=51$ \\
Mother & $\mathrm{L}=24.50 \mathrm{mg} / \mathrm{dL}$ & $\mathrm{P}=0.59 \mathrm{mg} / \mathrm{dL}$ & $\mathrm{L} / \mathrm{P}=41$ \\
\hline
\end{tabular}

Table 3. Lactacydemia, Pyruvicemia, and Lactate to Pyruvate (L/P) ratio in basal conditions and after exercise (AE) in the brother of the proposita.

\begin{tabular}{|c|c|c|c|c|c|c|}
\hline \multicolumn{3}{|c|}{ Lactacydemia } & \multicolumn{2}{|c|}{ Pyruvicemia } & \multicolumn{2}{|c|}{ L/P ratio } \\
\hline Brother & $\begin{array}{c}\text { Basal } \\
15.2 \mathrm{mg} / \mathrm{dL}\end{array}$ & $\begin{array}{c}\mathrm{AE} \\
29.9 \mathrm{mg} / \mathrm{dL}\end{array}$ & $\begin{array}{c}\text { Basal } \\
0.4 \mathrm{mg} / \mathrm{dL}\end{array}$ & $\begin{array}{c}\mathrm{AE} \\
0.25 \mathrm{mg} / \mathrm{dL}\end{array}$ & $\begin{array}{c}\text { Basal } \\
\mathrm{L} / \mathrm{P}=35\end{array}$ & $\begin{array}{c}\mathrm{AE} \\
\mathrm{L} / \mathrm{P}=119\end{array}$ \\
\hline
\end{tabular}


exercise L/P reached the value of 130 . Lactate dehydrogenase (LDH) was intermittently high (294-519 IU/L; normal value: 84$361 \mathrm{IU} / \mathrm{L})$.

The cariotype was normal $(46, \mathrm{XX})$. AGH was negative. The research of fragile $\mathrm{X}$ (gene FMRl) showed the presence of two normal alleles, without occurrence of mutations. Thin Layer Chromatography (TLC) of oligosaccharydes was normal. Mucopolysaccharides-glycosaminoglycans (GAG) in urine resulted in $24 \mathrm{mg} / \mathrm{mg}$ creatinine (normal values: $3-30 \mathrm{mg} / \mathrm{mg}$ ). Total urinary mucopolysaccharides were $10.8 \mathrm{mg}$ /day (normal value: $25-30$ $\mathrm{mg}$ /day). Electrophoresis of mucopolysaccharides did not show abnormality.

Electromyography (EMG) demonstrated reduced duration of some Motor Unit Potentials (MUPs); the amplitude of potentials was normal. The Maximal Conduction Velocity (MCV) of motor fibres of the right peroneal nerve was normal. Somato Sensorial Conduction (SSC) of inferior limbs was bilaterally low and spinogram demonstrated unidentified cortical components; peripheral components were normal. Muscular biopsy of left quadriceps muscle at 13 years of age showed fibre anisometry with normal hypotrophic and tendential hypertrophic fibers without degenerative signs; neither glycid nor lipid pathologic accumulation was observed with oil red and periodic acid-Schiff staining. Nicotinamide adenine dinucleotide, succinate dehydrogenase, cytochrome c oxidase, phosphorylase, phosphofructokinase, ATPase were normal (Gomori trichrome stain). A definite prevalence of first type fibres (oxidative fibres) was observed with ATP-ase stain.

Also the patient II-1, brother of the proposita, presented OAVS showing slight hemifacial microsomia, right ptosis, convergence weakness, slightly malformed ears, prolapsus of the anterior mitral leaflet with normal aorta. The results of basal normal lactacidemia $(15.2 \mathrm{mg} / \mathrm{dL})$ and pyruvicemia $(0.4 \mathrm{mg} / \mathrm{dL})$ with $\mathrm{L} / \mathrm{P}$ ratio $=35$, increased lactacidemia after exercise to $29.9 \mathrm{mg} / \mathrm{dL}$ and decreased pyruvicemia to $0.25 \mathrm{mg} / \mathrm{dL}$ with $\mathrm{L} / \mathrm{P}$ ratio=112 were typical of respiratory chain (OXPHOS) disease. ${ }^{19}$ Headache from the first years of life with normal EEG and normal fundus oculi were signaled.

The son of patient II-1, patient III-1, showed hemifacial microsomia, bilaterally down sided, grossly formed ears, hemihypotrophy of left leg muscles, incomplete Right Branch Block (RBB). These symptoms were typical of OAVS and partially of Chronic Progressive External Ophthalmoplegia (CPEO) phenotype.

The history of family demonstrated that the father (patient I-1) of the proposita was in good health conditions with basal hyperlactacidemia; the mother (patient I-2) presented basal hyperlactacidemia and mild hypoacusia.

In summary, the proposita showed OAVS associated to PEO, hyperlactacidemia and hypogonadism; her brother presented OAVS with PEO and hyperlactacidemia; the nephew of proposita presented OAVS with myopathy signs; father and mother of proposita presented hyperlactacidemia. In this family the OAVS diagnosis was proposed on the basis of clinical features.

\section{Discussion and Conclusions}

Ear abnormalities and hemifacial microsomia, i.e. the minimal features accepted for OAVS diagnosis, were present in three out of five members of this family in two generations; this condition allows the diagnosis of familial autosomal dominant inheritance. ${ }^{13}$ Chromosome abnormalities were not demonstrated in the proposita, and AGH screening was negative. The diagnosis of OAVS was done on the basis of clinical symptoms, i.e. hemifacial microsomia, malformed ears, right eye microphthalmia, antimongoloid palpebral slang, malar hypoplasia, flat nasal root, teeth malocclusion with enamel hypoplasia, transmission hypoacusia, spondilolysis and spondilolysthesis. Symptoms of myopathy associated to OAVS, i.e. right palpebral ptosis, convergence weakness of the ocular motility, fissure between velum and posterior pharingeal wall during fonation with disphonia (due to hyposthenia of musculus elevator palati and musculus constrictor pharingeus), dysphagia, generalized muscular hypotonia and hypotrophy mainly of inferior limbs, with weak Achilles reflex and bilateral pes planus valgus pronatus, were present. Myopathic-type reduced duration of some MUPs was recorded with EMG; the prevalence of type 1, rich in mitochondria, oxydative fibres (normal value $=50 \%$, as reported by Dubowitz et $a l .^{20}$ ) observed in the biopsy was compensatory, and indicated the occurrence of a mitochondrial disease ${ }^{21}$ with apparently normal OXPHOS. Elevated LDH and hyperlactacidemia with high $(>20)$ $\mathrm{L} / \mathrm{P}$ ratio were typical of mitochondrial disease with involvement of respiratory chain and were connected to cortical atrophy with hydrocephalus and oligomenorrea. The phenotype of myopathy pointed out progressive external ophthalmoplegia (PEO) associated to OAVS phenotype.

OAVS, in which Goldenhar Syndrome is included, is considered a neurocristopathy. ${ }^{6,22,23}$ In this disease the presence of malformations deposes for a disorder of blastogenesis (the period of 28 days from the ovum fecondation to the end of gastrulation), when cardio-angiogenesis, meso-nephrogenesis, body axis formation, and neurulation occur and somites are formed ${ }^{24}$. It was hypothesized that OAVS is due to an abnormal right-left body axis development during blastogenesis with facial maturation asymmetry. ${ }^{24,25}$

Neurulation is strictly connected to NCC migration, to five branchial arches formation, and to CNS development ${ }^{4}$. The structure of every branchial arch is complex and comprises ectodermal, mesodermal, endodermal, and NC-derived cells. ${ }^{26}$ The epidermal structures originate from the ectoderm; connectival, cartilagineous, and osseous structures originate from the mesoderm, populated by NCC; lining epithelium, thyroid and parathyroid glands arise from the endoderm. ${ }^{26}$

The alterations of facial osseous, cartilagineous, vascular and peripheral nerve structures are attributed to abnormalities of NCC proliferation and migration ${ }^{27}$ in the first and second branchial arches during the $4^{\text {th }}-5^{\text {th }}$ embryonic weeks and/or to the integration with tissues. ${ }^{28}$ Some homeobox genes $(B A P X 3, M S X)^{29}$ are present in $\mathrm{NCC}$, as well as some factors (FGF 8, FGF 10) $)^{30,31}$ which are relevant for the connection of NCC with the tissues in the first and second branchial arches; the pathology of NCC may interfere with the subsequent pathological development of ear and maxillomandibular structures. ${ }^{6,29}$

In humans, abnormality of NCCs may cause many facial malformations as observed in neurocristopathies, ${ }^{31}$ such as in the Waardenburg syndrome (in some cases due to $P A X 3$ gene mutation $)^{31,32}$ and in Treacher Collins - Franceschetti syndrome, due to mutations in the TCOF1, POLR1C, or POLR1D gene. ${ }^{33,34}$

The aetiology of OAVS is heterogeneous: the syndrome is consequent to genetic, environmental and epigenetic factors. $2,12,35$ The syndrome presents a genetic basis. Currently, growing factors depose for the inheritance of OAVS; in familial cases it seems more likely a Mendelian inheritance. ${ }^{2}$ Sporadic cases may have polygenic or multifactorial aetiology. OAVS is observed in families with dominant or recessive autosomal inheritance; in members of these families, isolated symptoms without the complete syndrome were also reported. ${ }^{12,13}$ OAVS has been reported in association with 
various chromosome rearrangements ${ }^{2}$, but chromosome aberrations do not seem to be a major cause of the syndrome. ${ }^{36}$ The molecular basis of OAVS is still unclear. ${ }^{12,13}$ Some genes were candidates, because associated with OAVS cases, but a conclusive study on genetic aetiology was not reported. ${ }^{2}$ In a family with apparent autosomal dominant inheritance, a linkage to a region of $10.7 \mathrm{cM}$ on the chromosome 14q32 containing GOOSECOID gene $(G S)$ was reported $^{37} G S$ is expressed in branchial arches during the development and has been suggested to play a role in hemifacial microsomia. ${ }^{37}$ Recently, a microdeletion $22 \mathrm{q} 11.2$ in a patient with OAVS mapped in the Di George - velocardial syndrome (VCS) region, non overlapping to OAVS with 22q11 deletion was reported by Digiglio et al.; ${ }^{38}$ it may cause a similar OAVS phenotype, thus pointing out a possible regulatory mechanism in the aetiology of OAVS, acting also on 22q11.2 mapped genes involved in NCCs and branchial arches development. ${ }^{35}$

Also environmental factors, i.e. maternal diabetes, ${ }^{39}$ cocaine, ${ }^{27}$ thalidomide, ${ }^{40}$ vasoactive drugs assumption during pregnancy, may play a role in the pathogenesis of the syndrome, but predisposing factors as twinning ${ }^{41}$ and reproductive techniques are relevant, because an excess of OAVS was reported in twinning and in children born from reproductive techniques. ${ }^{41,42}$

The mother of our patient showed hyperlactacidemia, a condition which may be present in decompensated diabetic mothers during pregnancy. We can hypothesize that mother hyperlactacidemia and her own genetically induced hyperlactacidemia may have acted in the proposita, inducing or aggravating the malformation symptoms of OAVS as in diabetic mothers. Epigenetic mechanisms are considered in OAVS etiology. The syndrome is consequent to the derangement of the first and second branchial arches, NCC-derived transitory structures strictly connected to NCC proliferation, migration and interaction with tissues. ${ }^{8}$ Epigenetic mechanisms are important in inducing OAVS, acting on the production or interaction of NCC with the environment. ${ }^{43}$ Monozygotic twinning and assisted reproduction ${ }^{42}$ may predispose to epigenetic modifications leading to histone acetylation-dependent imbalance of the allelic expression of the $B A P X 1$, a gene important in mandible development, as reported in five patients with OAVS. ${ }^{44}$ Currently, a multifactorial aetiology is considered for OAVS. ${ }^{2}$

The recurrence of OAVS in families with an affected member and the presence of isolated symptoms of OAVS in family members depose for the heterogeneity of OAVS. More factors acting on reproduction-migration of cranial NCC (between the fourth and seventh week of pregnancy), on interaction with ectoderm, mesoderm or endoderm, ${ }^{2}$ and/or on abnormal function of genes expressed in ectoderm, mesoderm or endoderm of pharingeal arches are possible etiopathogenetic factors of OAVS. Currently, no genetic specific tests are available for OAVS and the diagnosis is clinical. ${ }^{2}$ Screening by AGH should be performed in OAVS patients to recognize recurrent risks of disease transmission. ${ }^{2}$

In our case, the AGH screening was negative, but clinical evidence of OAVS was present in proposita; in other members of family the basal symptoms of OAVS were present and the diagnosis was possible.

The proposita presented basal hyperlactacidemia $(29.1 \mathrm{mg} / \mathrm{dL})$ with elevated L/P ratio (54). After meal containing carbohydrates, glycemia was of non diabetic type, lactacidemia was raised (34.4 $\mathrm{mg} / \mathrm{dL})$ and persisted high $(33.1 \mathrm{mg} / \mathrm{dL})$ three hours after meal. Basal and after meal pyruvicemia showed slight modifications; L/P ratio was high ( $>20)$ after meal (one and three hours), deposing for a defect of electron transport of respiratory chain at the mitochondrial level, because hyperlactacidemia was permanent and reached the maximum level in the fed state, ${ }^{19}$ as in electron transport of respiratory chain disorders. Hyperlactacidemia was present in mother and father of proposita with L/P of 41 and 51, respectively; normal pyruvicemia was recorded. In the absence of diabetes, also these results depose for a respiratory chain disease. ${ }^{19}$

In the absence of shock and/or hypoxia, hyperlactacidemia is attributed to congenital conditions. ${ }^{45}$ In our cases hyperlactacidemia with raised $\mathrm{L} / \mathrm{P}$ ratio depose for a respiratory chain disorder, despite the apparent normality of mitochondrial enzymes at muscular biopsy. ${ }^{46}$ As a matter of fact, not always the biopsy is diagnostic in these disorders, as demonstrated in a case of CPEO with ptosis without hystochemical, biochemical and clinical muscular abnormalities, in which only the genetic study demonstrated a single mtDNA deletion. ${ }^{46}$ In three patients out of fourty having CPEO adult onset, ${ }^{47}$ of which eleven with hyperlactacidemia, the muscular biopsy was not diagnostic, two cases presented PolG1 mutation and one case a mtDNA deletion. These reports emphasize the relevance of genetic studies in association with clinical, histological and eventually genetic/familial pictures. Mitochondrial enzymes have a dual genetic origin, nuclear and mitochondrial. ${ }^{48}$ Both mendelian and maternal inheritance are reported. The knowledge of the type of inheritance may be adjuvant in the diagnosis of OXPHOS disease. PEO occurs in some forms of mitochondrial myopathy and can be sporadic or sometimes familial with autosomal dominant inheritance; in rare conditions, the dominant PEO inheritance was multisystemic and associated to hypogonadism. ${ }^{18,49}$ The muscular abnormalities were considered to be features of mitochondrial myopathy. ${ }^{18}$

In our patient PEO, anisometry with hypotrophic and hypertrophic fibres with prevalence of type 1 , and the electrophysiological results allowed the diagnosis of a typical form of respiratory chain disorder, i.e. the autosomal dominant progressive external ophthalmoplegia (adPEO). ${ }^{18}$ adPEO is a miopathy which occurs as a mitochondriopathy; this condition is due to a mtDNA mutation and is present as dominant. ${ }^{18} \mathrm{~A}$ late onset CPEO with recessive transmission is also described, ${ }^{18,44}$ with ocular and body muscle symptoms, hyperlactacidemia, Ragged Red Fibers (RRF) on biopsy, which may be associated to multisystem manifestations as migraine, polyneuropathy, diabetes with different phenotype. In adPEO, heteroplasmy (a condition in which normal and deleted mtDNA is present in all tissues) may explain the different results and the possible negativity of the biopsy in our patient. ${ }^{47}$

In a family with PEO autosomal dominant transmission was reported by Melberg et al. ${ }^{18}$ the ocular symptoms (ptosis and ophthalmoplegia or convergence weakness) were associated to limb weakness and wasting, Achilles areflexia, dysartria, dysphonia, raised $\mathrm{LDH}$, hyperlactacidemia at rest, inconstantly raised $\mathrm{CPK}$, ALT, GT, ALP in blood, normal motor nerve conduction, EMG of miopathyc type, sensory (sural) peripheral nerve involvement, and local responses. In advanced cases, muscle biopsy presented RRF and COX-negative fibres. In this family a different association of symptoms was possible, but the Authors ${ }^{18}$ state that the combination of PEO, Achilleus tendon areflexia, EMG of myopathic type, and abnormally low sural nerve conduction, if associated to distal vibratory sensory impairment, seems to be typical of this disease, underlining the possibility of the diagnosis on the basis of electrophysiological signs which are typical for this form. ${ }^{18}$

In our case, clinical and neurophysiological investigations showed a descent myopathy and weakness from cranial structures to inferior limbs related to age and disease duration. EMG was partially of myopathic type owing to the altered duration of some MUPs, sensory responses were reduced and cortical responses were 
not identified; these results were interpreted as the consequence of axonal neuropathy. ${ }^{18}$ In our case the maximal conduction velocity values were normal, but the sural sensitive responses were low, a finding which can be interpreted as an axonal involvement or a conduction failure. Achilles tendon reflex was weak as in a case described by Melberg et al. ${ }^{18}$ the negativity for RRF and COX staining may be explicated on the basis of heteroplasmy. ${ }^{50,51}$ The patient presented hypogonadism.

PEO with pigmentary retinopathy is on a disease spectrum with Kearns-Sayre syndrome (KSS), a disease beginning before twenty years of age and characterized by ophthalmoplegia, pigmentary retinopathy and having at least one of the following symptoms: ataxia, increase of CSF proteins, cardiac block, in which mtDNA deletion or Polg mutation/deletion were demonstrated. In KSS, Berio and Piazzi ${ }^{52}$ reported the association of hyperlactacidemia with facial abnormalities of neural crest cell-derived structures and attributed this association to the derangement of NCC, via abnormalities of branchial arches consequent to an early mtDNA mutation and OXPHOS derangement during blastogenesis.

Berio $^{53}$ reported the association of facial abnormalities with various mitochondrial diseases, notably with KSS and CPEO, via branchial arches abnormalities by scarce energy production during the critical period of embryogenesis causing neural crest cell gene abnormalities or NCC proliferation/migration and integration with tissues disorders. In our patient the association of respiratory chain disorder with some symptoms of OAVS deposes for a relationship between respiratory chain disorders and OAVS.

We assume that OXPHOS deficiency in embryo, by virtue of a disturbed oxygen metabolism, may alter directly face, muscles and brain energy production during the critical period of embryonic development, causing OAVS malformations and adPEO. ${ }^{53}$ In this view, OAVS with adPEO may be considered a neurocristopathy. Alternatively, dos Santos et al. ${ }^{35}$ hypothesize an altered genetic nuclear mechanism in OAVS; these Authors reported about a patient with OAVS and a microdeletion which mapped to the 22q11.21 region, i.e. to the typical Di George-velocardiofacial syndrome (VCFS).$^{35}$ Previously, Digiglio et al. ${ }^{38}$ reported, in a OAVS patient, a 22q11.2 deletion which mapped to the typical VCFS deletion segment. Since 22q11 non-overlapping deletions cause similar phenotypes, the Authors hypothesized a possible regulatory mechanism acting on 22q11.2 mapped genes (GSC2 and TBX1 which are important for first and second branchial arches and ear development, respectively) and on NCC development.

We hypothesize that in our case a double mechanism responsible for the OAVS and the adPEO, i.e. a nuclear and a mitochondrial mechanism responsible for malformations and hyperlactacidemia, respectively, exist. Alternatively, OXPHOS gene mutation acting on contiguous genes present in the $T B X 1$ region, via a regulatory mechanism interesting early NCC and branchial arches development, could cause the clinical symptomatology.

In the case of a proband with normal chromosomes and negative familial history, OAVS presents an empirical 2-3\% risk of recurrence in siblings ${ }^{2}$; but OAVS may show a recessive or dominant heritance in some families. To evaluate the recurrence of risk the research of minimal signs of OAVS, ${ }^{2}$ in which we can consider the myopathy, is necessary. Considering the findings of our case, the myopathy of OAVS, ${ }^{1}$ rarely reported in the literature, may be a sign which facilitates the diagnosis of OAVS, and may be added to the ocular, vertebral and auricular symptoms of this spectrum.

The hyperlactacidemia (basal, after meal, after physical exercise) in our patients led to the mitochondrial pathology domain, ${ }^{17}$ which may have been responsible of some symptoms (hydrocephaly, ocular muscle hypotonia); in general, lactacidemia may be a screening for the evaluation of a mitochondrial myopathy, ${ }^{17}$ and eventually for searching mtDNA mutation which may permit an early diagnosis and genetic counseil to parents. In our opinion, the demonstration of an associated mtDNA-OAVS pathology deposes for a metabolic energy defect in the pathogenesis of the malformations present in OAVS.

On the basis of this case it seems appropriate to search in every cases of OAVS for the presence of hyperlactacidemia which may depose for respiratory chain disorders. If our data will be confirmed, it could be allow to elucidate the pathogenesis of the disease which at present is still unclear.

Currently, the challenge is the identification of the metabolic and genetic bases of OAVS, a condition which is important for disease prevention.

\section{References}

1. Gorlin RJ, Luc KL, Jacobsen U, Goldschmidt E. Oculoauriculovertebral dysplasia. J Pediatr 1963;63:991-9.

2. Beleza-Meireles A, Clayton-Smith J, Saraiva JM, Tassabehji M. Oculo-auriculo-vertebral spectrum: a review of the literature and genetic update. J Med Genet 2014;51:635-45.

3. Goodman FR. Congenital abnormalities of body patterning: embryology revisited. Lancet 2003;362: 651-62.

4. Le Douarin NM, Kalcheim C. The neural crest. New York, USA: Cambridge University Press; 1999.

5. Couly G, Creuzet S, Bonnaceur S, et al. Interactions between Hox-negative cephalic neural crest cells and the foregut endoderm in patterning the facial skeleton in the vertebrate head. Development 2002;129:1061-73.

6. Stoll C, Viville B, Treisser A, Gasser B. A family with dominant oculoauriculovertebral spectrum. Am J Med Gen 1998;78:345-9.

7. Beck AE, Hudgins L, Hoyme HE. Autosomal dominant microtia and ocular coloboma: new syndrome or an extension of the oculo-auriculo-vertebral spectrum? Am J Med Genet A 2005; 134:359-62.

8. Berio A, Mangiante G, Oliaro E, Piazzi A. Oculoauriculovertebral syndrome with large cerebral cyst: affinity to holoprosencephaly. Min Pediat 2012;64:549-54.

9. Hartsfield J. Review of the etiologic heterogeneity of the oculoauriculo-vertebral spectrum (Hemifacial Microsomia). Orthodont Craniofacial Res 2007;10:121-8.

10. Cousley RR, Wilson DJ. Hemifacial microsomia: developmental consequence of perturbation of the auriculofacial cartilage model? Am J Med Genet 1992;42:461-6.

11. Rollnick BR, Kaye CI. Hemifacial microsomia and variants: pedigree data. Am J Med Genet 1983;15:233-53.

12. Tasse C, Böhringer S, Fischer S, et al. Oculo-auriculo-vertebral spectrum (OAVS): clinical evaluation and severity scoring of 53 patients and proposal for a new classification. Eur J Med Genet 2005;48:397-411.

13. Tasse C, Mayewski F, Bohringer S, et al. A family with dominant oculoauriculovertebral spectrum. Clin Dysmorphol 2007;16:1-7.

14. Kaye CI, Martin AO, Rollnick BR, et al. Oculoauriculovertebral anomaly: Segregation analysis. Am J Med Genet 1992;43:913-7.

15. Berio A. La oftalmoplegia esterna cronica progressiva. Min Pediat 1994;46:365-70.

16. Luquetti DV, Heike CL, Hing AV, et al. Microtia: Epidemiology and genetics. Am J Med Genet 2012;158A:124-39. 
17. Shoffner JM. Oxidase phosphorilation diseases. In: CR Scriver, AL Beaudet, WS Sly, D Valle, B Childs, KW Kinzler, B Vogelstein, eds. The metabolic and molecular bases of inherited diseases. McGraw-Hill Education - Europe: New York, USA; 2001. pp 2367-2423.

18. Melberg A, Lundberg PO, Henriksson KG, et al. Muscle-nerve involvement in autosomal dominant progressive external ophthalmoplegia with hypogonadism. Muscle Nerve 1996;19:751-7.

19. Poggi Travert F, Martin O, Billett de Villemeur T, et al. Metabolic intermediates in lactic acidosis. Compounds, samples and interpretation. J Inher Metab Dis 1996;19:478-88.

20. Dubowitz V. Enzyme histochemistry of skeletal muscle. J Neurol Neurosurg Psychiatry 1965;28:516-24.

21. Koo B, Becker LE, Chuang S, et al. Mitochondrial encephalomyopathy, lactic acidosis, stroke-like episodes (MELAS): Clinical, radiological, pathological, and genetic observations. Ann Neurol 1993;34:25-32.

22. Bolande RP. Neurocristopathy: its growth and development in 20 years. Pediatr Pathol Lab Med 1997;17:1-25.

23. Stromland K, Miller M, Sjogreen C, et al. OAV spectrum. Am J Med Gen 2007;143A:1317-25.

24. Opitz JM, Zanni G, Reynolds JF, Gilbert-Barness E. Defects of blastogenesis. Am J Med Gen 2002;115:269-80.

25. Piazzi A. Le malattie mitocondriali con turbe della fosforilazione ossidativa. Aspetti diagnostici, odontoiatrici, terapeutici e pedagogici. Università di Genova, Tesi di Dottorato in Pedodontologia. 1994.

26. Smith DW, Graham JM Jr. Fetal alcohol syndrome in child whose parents had stopped drinking. Lancet 1979;2:527.

27. Nijhawan N, Morad Y, Deigel-Bartelt J, Levin AV. Caruncle abnormalities in the oculoauriculovertebral spectrum. Am J Med Gen 2002;113:320-5.

28. Gammill LS, Bronner-Fraser M. Neural crest specification: migrating into genomics. Nature Rev Neurosci 2003;4:795-805.

29. Hill AD, Chang B, Hill RS, et al. A 2 MB critical region implicated in the microcephaly associated with terminal $1 \mathrm{q}$ deletion syndrome. J Med Genet 2007;143A:1962-8.

30. Creuzet S, Schuler B, Couly G, Le Douarin NM. Reciprocal relationships between Fgf8 and neural crest cells in facial and forebrain development. PNAS 2004;101:4843-7.

31. Helms JA, Cordero D, Tapadia MD. New insights into craniofacial morphogenesis. Development 2005;132:851-61.

32. Couly G. A new concept of Pierre Robin syndrome and disease: dysneurulation of the rhombencephalon. Rev Stomatol Chir Maxillofac 1983;84:225-32.

33. Dauwerse JG, Dixon J, Seland S, et al. Mutations in genes encoding subunits of RNA polymerases I and III cause Treacher Collins syndrome. Nat Genet 2011;43:20-2.

34. Schaefer E, Collet C, Genevieve D, et al. Autosomal recessive POLR1D mutation with decrease of TCOF1 mRNA is responsible for Treacher Collins syndrome. Genet Med 2014; $16: 720-4$

35. dos Santos CPA, De Oliveira SF, Freitas EL, et al. Nonoverlapping 22q11.2 microdeletions in patients with oculo-auriculo-vertebral spectrum. Am J Med Genet
2013;164A:551-3.

36. Kumar A, Friedman JM, Taylor GP, Patterson MWH. Pattern of cardial malformation syndrome in oculoauriculovertebral spectrum. Am J Med Gen 1993;146:423-6.

37. Kelberman D, Tyson J, Chandler DC, et al. Hemifacial microsomia: progress in understanding the genetic basis of a complex malformation syndrome. Hum Genet 2001;109:638-45.

38. Digiglio MC, McDonald-McGinn DH, Heike C, et al. Three patients with oculo-auriculo-vertebral spectrum and microdeletion 22q11.2. Am J Med Genet A 2009;149A:2860-4.

39. Wang R, Martinez-Frias ML, Graham JM. Infants of diabetic mothers are at increased risk for the oculoauriculovertebral sequence: a case based and case-control approach. J Pediat 2002;141:611-7.

40. Newman LM, Hedrickx AG. Temporomandibular malformations in the Bonnet monkey (Macaca radiata) fetus following maternal ingestion of thalidomide. J Craniof Genet Dev Biol 1985;5:147-57.

41. Wieczorek D, Ludwig M, Boehringer S, et al. Reproduction abnormalities and twin pregnancies in parents of sporadic patients with oculo-auriculo-vertebral spectrum/Goldenhar syndrome. Hum Genet 2007;121:369-76.

42. Balci S, Engiz O, Alikasifoglu M, et al. Association of assisted reproductive technology with twinning and congenital anomalies. Indian J Pediatr 2008;75:638.

43. Haberland M, Mokalled MH, Montgomery RL, Olson EN. Epigenetic control of skull morphogenesis by histone deacetylase 8. Genes Dev 2009;3:1625-30.

44. Fischer S, Lüdecke H-J, Wieczorek D, et al. Histone acetylation dependent allelic expression imbalance of BAPX1 in patients with the oculo-auriculo-vertebral spectrum. Human Molec Genet 2006;15:581-7.

45. Tarlov MJ, Lake BD, Lloyd JK. Chronic lactic acydosis in association with myopathy. Arch Dis Child 1973;48:489-92.

46. Schaefer AM, Blakely EL, Griffiths PG, et al. Ophthalmoplegia due to mitochondrial DNA disease: the need for genetic diagnosis. Muscle Nerve 2005;32:104-7.

47. Pfeffer G, Sirrs S, Kevin Wade N, Mezei MM. Multisystem disorder in late-onset chronic progressive external ophthalmoplegia. Can J Neurol Sci 2011;38:119-23.

48. Di Mauro S, Schon EA. Mitochondrial respiratory-chain diseases. N Engl J Med 2003;348:2656-68.

49. Lundberg PO. Observations on endocrine function in ocular myopathy. Acta Neurol Scand 1966;42:39-61.

50. Johnson MA, Turnbull DM, Dick DJ, Scherratt HAS. A partial deficiency of cytochrome c oxidase in chronic progressive external ophthalmoplegia. J Neurol Sci 1983;60:31-53.

51. Piazzi A, Berio A. Facial anomalies in patients with cytochrome-c-oxidase (COX) deficiency: a dysneurulation. Minerva Pediatrica 2004;56:547-50.

52. Berio A, Piazzi A. Facial anomalies in a patient with cytochrome-oxydase deficiency and subsequent Kearns-Sayre syndrome with growth hormone deficiency. Minerva Med 2007;98:81-5.

53. Berio A. Metabolic syndromes and neural crest development. J Biol Res 2011;84:73-5. 